\title{
Examining the Interrelations Among Objective and Subjective Health Literacy and Numeracy and Their Associations with Health Knowledge
}

\author{
Erika A. Waters, $P h D, M P H^{7}$, Caitlin Biddle, $P h D^{2}$, Kimberly A. Kaphingst, $S c D^{3}$, \\ Elizabeth Schofield, $\mathrm{MPH}^{4}$, Marc T. Kiviniemi, $\mathrm{PhD}^{2}$, Heather Orom, $\mathrm{PhD}{ }^{2}$, Yuelin Li, $\mathrm{PhD}{ }^{4}$, and \\ Jennifer L. Hay, PhD
}

'Washington University in St. Louis, St. Louis, MO, USA; ${ }^{2}$ University at Buffalo - State University of New York, Buffalo, USA; ${ }^{3}$ University of Utah, Salt Lake City, USA; ${ }^{4}$ Memorial Sloan Kettering Cancer Center, New York, USA.

\begin{abstract}
BACKGROUND: Health literacy and numeracy influence many health-related behaviors and outcomes. Health literacy and numeracy have been assessed objectively and subjectively, but interrelationships among the measures and the consistency of their association with health knowledge have not been examined.
\end{abstract}

OBJECTIVE: To increase understanding of the structure and interrelations among objective and subjective health literacy and numeracy and how these constructs relate to knowledge of risk factors of two major diseases.

DESIGN: Secondary analysis of cross-sectional survey data, weighted to be representative of the general US population of non-institutionalized adults.

PARTICIPANTS: Participants $(N=1005,55.2 \%$ response rate) were recruited from GfK KnowledgePanel. The unweighted sample included 52\% women, 26\% racial/ ethnic minorities, and $37 \%$ with no college experience.

MAIN MEASURES: Objective health literacy, subjective health literacy, objective numeracy, subjective numeracy. Objective and perceived knowledge of diabetes and colon cancer risk factors were also assessed.

KEY RESULTS: Confirmatory factor analyses indicated that a model with correlated $(r=0.16-0.56)$ but separate factors for each of the four literacy/numeracy constructs best fit the data (RMSEA $=0.055$ (95\% CI 0.049-0.061), $\mathrm{CFI}=0.94$ ). Consistency between measures in classifying people as having adequate or limited health literacy or numeracy was 60.9-77.1\%, depending on the combination of measures. All four literacy/numeracy constructs were independently associated with objective diabetes knowledge and objective colon cancer knowledge (all ps <.04). Subjective (but not objective) literacy and numeracy measures were associated with diabetes perceived knowledge

An earlier version of the present manuscript was presented as a poster at the 2017 Annual Meeting of the Society for Behavioral Medicine in San Diego, CA.

Electronic supplementary material The online version of this article (https://doi.org/10.1007/s11606-018-4624-2) contains supplementary material, which is available to authorized users.

Received January 10, 2018

Revised May 22, 2018

Accepted July 25, 2018

Published online August 17, 2018 (all $p s<.02$ ). No literacy/numeracy measures were associated with perceived colon cancer knowledge.

CONCLUSIONS: We identified objective and subjective health literacy and numeracy as four distinct but related concepts. We also found that each construct accounts for unique variance in objective (but not subjective) disease knowledge. Until research uncovers what psychological processes drive subjective measures (e.g., motivation, self-efficacy), research investigating the relationship between health literacy and health outcomes should consider assessing all four measures.

KEY WORDS: health literacy; numeracy; knowledge; diabetes; colon cancer.

J Gen Intern Med 33(11): 1945-53

DOI: $10.1007 / \mathrm{s} 11606-018-4624-2$

(C) Society of General Internal Medicine 2018

\section{INTRODUCTION}

Preventing disease and maintaining wellness require patients to take considerable responsibility for their health. ${ }^{1}$ Consequently, individuals must know what factors influence disease risk. However, many individuals have limited ability to understand and use written, verbal, and/or numeric health information. ${ }^{2,}{ }^{3}$ Limited health literacy and numeracy are associated with poorer health indicators and outcomes, including increased hospitalizations, lower use of health promotion and disease detection services, higher prevalence and severity of chronic disease, higher medication non-adherence, and lower health behavior engagement. ${ }^{4-7}$ Lower health literacy and numeracy are also associated with lower knowledge of disease risk factors. ${ }^{5,}{ }^{8-10}$ Thus, limited health knowledge may contribute to the association between lower health literacy/numeracy and poor health outcomes. ${ }^{7}$

However, unresolved questions exist about the nature and uniqueness of health literacy and numeracy, including whether numeracy is a distinct construct or a sub-component of health literacy, and whether there are differences between objective measures of health literacy and numeracy (which have answers that can be categorized as correct or incorrect), ${ }^{11-13}$ versus subjective measures (which ask patients to evaluate their own abilities). ${ }^{14,15}$ Both questions are central to understanding the nature 
of these constructs, their relation to health knowledge, and which tools should be used in scientific inquiry and clinical practice. Prior research focused primarily on comparing objective and subjective measures of health literacy ${ }^{14,}{ }^{16}$ or objective and subjective measures of numeracy, ${ }^{15}$ but few studies have examined all four constructs simultaneously. Such a study would provide insight into whether each of the four constructs contributes independently to the prediction of key outcomes.

We sought to improve understanding of the nature of health literacy and numeracy. Specifically, whether objective and subjective measures of health literacy and numeracy represent four separate constructs, one overarching construct, or two constructs characterized as either subjective versus objective or health literacy versus numeracy. We also investigated the extent to which the four measures make unique contributions to lay people's objective and perceived health knowledge. Objective knowledge is important for determining whether to take a health-protective action. ${ }^{17}$ Perceived knowledge, or how much information people feel they have, may be related to an individual's sense of the appropriateness of taking action. ${ }^{18}$

We (1) used confirmatory factor analysis (CFA) to determine whether objective and subjective health literacy and numeracy should be considered distinct constructs; (2) examined the extent to which objective and subjective measures categorize the same people as having adequate health literacy or numeracy; and (3) examined the extent to which health literacy and numeracy measures categorize the same people as having adequate facility with health information. We also examined whether (4) objective disease knowledge is predicted better by objective or subjective health literacy and/or numeracy measures and (5) subjective knowledge is better predicted by one of the health literacy/numeracy measures.

We examined these issues in two disease contexts: colon cancer and diabetes. Examining these diseases provided insight into the generalizability of our findings to diseases that vary in prevalence, risk factors, emotional responses, and treatment type and duration. ${ }^{19-22}$

\section{METHODS}

\section{Participants and Procedure}

All study materials and procedures were approved by the University of Buffalo Institutional Review Board, but recruitment and data collection were conducted through GfK. GfK is an international research company that uses address-based random sampling to create an Internet-based survey panel that is comprised of a population-based sample of the non-institutionalized US population. GfK provides panelists with a free personal computer and/or Internet connection if they need one. For this study, GfK randomly selected potential participants from its panel and emailed them an invitation to complete the questionnaire. Reminder emails were sent after 3 days and reminder phone calls 3-4 days after that. Taking the survey took approximately
20 min. Participants received points that could be redeemed for products in compensation for their participation.

Eligibility criteria were as follows: at least 18 years old, communicate in English, and no personal history of both colon cancer and diabetes mellitus. Panelists with a diagnosis of either colon cancer or diabetes were eligible. Of 1818 panelists screened, 1007 (55.4\%) agreed to participate and provided valid data. Of these, two failed the eligibility screener and were withdrawn from the study. Of the 1005 remaining eligible respondents, 112 reported having diabetes and therefore only received questions about colon cancer, and 6 reported having colon cancer and only received questions about diabetes. The remaining 887 respondents did not report being diagnosed with either illness, and received questions about both colon cancer and diabetes. To prevent existing disease knowledge from biasing knowledge outcomes, we did not ask respondents to answer questions about a disease for which they had a diagnosis.

\section{Measures}

The survey included items assessing demographics, health history, and several psychosocial constructs. Below, we describe the measures used for this paper. The full survey can be obtained from the corresponding author.

Objective Health Literacy. We administered the 6-item Newest Vital Sign (NVS). ${ }^{23}$ Items were scored correct or incorrect, and the correct items were summed. Missing items were considered incorrect. Scores of 0-3 indicated limited objective health literacy; scores of 4-6 indicated adequate objective health literacy.

Subjective Health Literacy. We administered the 3-item Brief Health Literacy Screener (Cronbach's $\alpha=0.67)^{24}$. One item was reverse coded and then summed with the other 2 items. Then, the summed values were reverse scored so higher numbers indicated higher health literacy. Scores of 0-6 indicated limited subjective health literacy; scores of 7-12 indicated adequate subjective health literacy.

Objective Numeracy. We adapted three of four objective numeracy items ${ }^{13,16,25}$ to be directly related to health instead of a lottery context. Items were scored correct or incorrect and then summed. Missing items were considered incorrect. Scores of 0-2 indicated limited objective numeracy; scores of 3-4 indicated adequate objective numeracy.

Subjective Numeracy. We administered the Subjective Numeracy Scale- $3^{15}$ (Cronbach's $\alpha=0.85$ ). Items were summed. Based on a median split, scores of 0-12 indicated limited subjective numeracy; scores 13-18 indicated adequate subjective numeracy.

Objective Knowledge. We assessed knowledge by asking whether "each item below lowers the risk of someone 
getting [diabetes/colon cancer], has no effect on the risk, or raises the risk of someone getting [diabetes/colon cancer]." A do not know option was provided. The five potential diabetes risk-increasing and risk-decreasing factors were as follows: smoking, eating a healthy diet, having a blood relative with diabetes, older age, and staying at a healthy weight. ${ }^{19}$ The five potential colon cancer risk-increasing and risk-decreasing factors were as follows: older age, high-fat diet, regular physical activity, smoking, and having a blood relative with colon cancer. ${ }^{20}$ Items were scored correct or incorrect and correct scores were summed. Missing items and do not know responses were considered incorrect. Two foils were included for each disease, but not included in the summed score. The possible range for each knowledge scale was $0-5$.

Perceived Knowledge. Given the dearth of prior research in the area, we assessed perceived knowledge with one authorcreated item: "I feel like I have enough information to know my risk of getting diabetes/colon cancer (1) strongly disagree - (4) strongly agree."

Demographics. GfK provided age, sex, race/ethnicity, education, income, employment status, marital status, and geographic location (metro/non-metro).

\section{Analysis Plan}

Statistical analyses were performed using MPlus $8^{26}$ and Stata $14 .^{27}$ To examine the number of constructs assessed by the health literacy and numeracy measures, we used confirmatory factor analysis (CFA) with robust weighted least squares estimators. We first estimated a model with objective health literacy, subjective health literacy, objective numeracy, and subjective numeracy as four separate "latent factors" (i.e., concepts that cannot be directly observed and therefore must be measured through indirect strategies such as survey items). To accomplish this, we instructed MPlus that the subjective numeracy items should be considered one "subjective numeracy" factor and the subjective health literacy items should be considered one "subjective health literacy" factor. We performed the same process for each of the two objective measures. The exception was that, because answers for the sixth objective health literacy item depended on answers from the fifth item, we only included the first five objective health literacy items. A model including the sixth item showed the same factor structure but slightly worse model fit, indicative of a more complex model that does not improve prediction.

We examined the overall model fit and the intercorrelation matrix among the four factors. To compare the plausibility of the four-factor model to other models, we estimated three additional CFA models: (a) a two-factor model with all the objective and subjective numeracy items "loading on" (or "belonging to") one numeracy latent factor and all the objective and subjective health literacy items loading on one health literacy latent factor; (b) another two-factor model with all the objective health literacy and numeracy items loading on one objective latent factor and all the subjective heath literacy and numeracy items loading on a separate subjective latent factor; and (c) a onefactor model with all items loading on one latent factor.

To examine overlap among the four measures, we conducted cross tabs. To test the predictive power of the measures, we conducted separate weighted linear and logistic regression models for each predictor (i.e., objective and subjective health literacy and numeracy) and each outcome (i.e., objective and subjective knowledge of diabetes and colon cancer). We tested unadjusted models and models adjusting for demographics and using the weights provided by GfK. Lastly, we tested a model that included all the health literacy and numeracy measures as predictors in the same regression.

\section{RESULTS}

The analytic sample included 1005 participants. Table 1 contains descriptive information about the sample demographics and key variables of interest. Weighted analyses indicate that $25.7 \%$ of the US population has limited objective health literacy, $10.6 \%$ has limited subjective health literacy, $41.8 \%$ has limited objective numeracy, and $44.1 \%$ has limited subjective numeracy.

\section{Number of Constructs}

Full details on the CFA model can be obtained from the corresponding author. Briefly, every individual survey item loaded significantly and in the expected direction on its hypothesized latent factor. As shown in the Online Supplement Table 1, the fit indices indicated that the four-factor solution provides a good fit to the data, meeting recommended guidelines for good model fit for the root mean square approximation (RMSEA) and comparative fit index (CFI) ${ }^{28,}{ }^{29}$ The fourfactor model also provides a meaningfully better fit to the data than do any of the alternative models (all chi-square difference tests using the DIFFTEST MPlus procedure were significant and the RMSEA fit indices have non-overlapping confidence intervals). Moreover, the fit of the four-factor solution indicates that the factors represent separate and distinct constructs despite their intercorrelations (Tables 2 and 3).

\section{Overlap Between Objective and Subjective Measures}

For objective and subjective health literacy, 791 (77.11\% weighted) participants were classified as limited on both or adequate on both (Table 4). When there was a discrepancy, more people were classified as adequate on subjective health literacy and limited on objective health literacy $(n=161$, $18.80 \%$ weighted) than the converse ( $n=39,4.08 \%$ weighted).

For objective and subjective numeracy, 682 (68.08\% weighted) were classified the same on both measures (Table 4). The 
Table 1 Participant Demographics $(N=1005)$

\begin{tabular}{|c|c|c|c|}
\hline Demographic & Number & $\%$ or mean (SD) & $\%$ or mean $(\mathrm{SD})^{* \dagger}$ \\
\hline Sex (female) & 521 & $51.84 \%$ & $51.87 \%$ \\
\hline Age & 1005 & $50.02(17.18)$ & 46.93 (17.72) \\
\hline \multicolumn{4}{|l|}{ Race/ethnicity } \\
\hline White, non-Hispanic & 741 & $73.73 \%$ & $64.79 \%$ \\
\hline Black, non-Hispanic & 98 & $9.75 \%$ & $11.72 \%$ \\
\hline Hispanic & 97 & $9.65 \%$ & $15.54 \%$ \\
\hline Non-specific & 69 & $6.87 \%$ & $7.95 \%$ \\
\hline Income (less than $\$ 49,999$ ) & 342 & $34.03 \%$ & $38.63 \%$ \\
\hline \multicolumn{4}{|l|}{ Education } \\
\hline Less than high school & 77 & $7.66 \%$ & $12.07 \%$ \\
\hline High school & 295 & $29.35 \%$ & $29.67 \%$ \\
\hline Some college or more & 633 & $62.99 \%$ & $58.25 \%$ \\
\hline \multicolumn{4}{|l|}{ Employment status } \\
\hline Employed & 576 & $57.31 \%$ & $57.24 \%$ \\
\hline Retired & 222 & $22.09 \%$ & $19.16 \%$ \\
\hline Unemployed & 207 & $20.60 \%$ & $23.60 \%$ \\
\hline \multicolumn{4}{|l|}{ Marital status } \\
\hline Married/partnered & 611 & $60.80 \%$ & $56.01 \%$ \\
\hline Never married & 228 & $22.69 \%$ & $27.66 \%$ \\
\hline Divorced/separated/widowed & 166 & $16.52 \%$ & $16.33 \%$ \\
\hline Metro status (non-metro) & 164 & $16.32 \%$ & $15.00 \%$ \\
\hline Key outcomes & $N$ & $\%$ or mean $(\mathrm{SD})$ & $\%$ or mean $(\mathrm{SD}) *$ \\
\hline Objective health literacy (limited) & 206 & $20.50 \%$ & $25.72 \%$ \\
\hline Subjective health literacy (limited) & 79 & $7.97 \%$ & $10.61 \%$ \\
\hline Objective numeracy (limited) & 378 & $37.61 \%$ & $41.77 \%$ \\
\hline Subjective numeracy (limited) & 393 & $39.66 \%$ & $44.11 \%$ \\
\hline Diabetes knowledge, $0-5$ & 893 & $3.80(1.28)$ & $3.68(1.38)$ \\
\hline Colon cancer knowledge, $0-5$ & 999 & $3.38(1.59)$ & $3.26(1.65)$ \\
\hline Diabetes perceived knowledge, $1-4$ & 886 & $2.84(0.80)$ & $2.79(0.82)$ \\
\hline Colon cancer perceived knowledge, $1-4$ & 994 & $2.58(0.86)$ & $2.52(0.87)$ \\
\hline
\end{tabular}

*Weighted

${ }^{\dagger}$ Percentages only represent valid percentages

discordance between measures was approximately equal; 142 ( $14.50 \%$ weighted) participants were classified as adequate on subjective numeracy and limited on objective numeracy, and the converse for 167 (17.43\% weighted) participants.

\section{Overlap Between Health Literacy and Numeracy}

Objective measures of health literacy and numeracy placed 707 (70.33\% weighted) participants in identical categories (Table 4). Differences were mainly due to participants having adequate health literacy and limited numeracy $(n=235$, $22.86 \%$ weighted). Only 63 (6.81\% weighted) participants had adequate numeracy but limited health literacy.

For both subjective measures, there was $60.86 \%$ (weighted) overlap $(n=631)$ (Table 4$)$. The main difference was because 329 (36.17\% weighted) participants believed they had adequate health literacy but limited numeracy. In contrast, 21
(2.97\% weighted) participants believed they had adequate numeracy, but limited health literacy.

\section{Predicting Objective and Perceived Disease Knowledge from Health Literacy and Numeracy}

Table 5 presents the unadjusted and adjusted associations between the individual health literacy and numeracy measures and objective and subjective disease knowledge. In unadjusted and adjusted models, higher objective knowledge of diabetes and colon cancer was statistically significantly associated with adequate objective and subjective health literacy and numeracy. However, the relationships were different for perceived knowledge. Higher perceived diabetes knowledge was statistically significantly related to adequate subjective (but not objective) health literacy and numeracy. Perceived knowledge

Table 2 Model fit indices for each of four hypothesized models

\begin{tabular}{|c|c|c|c|}
\hline Model & RMSEA (95\% CI) & CFI & CHI SQ (DF) ${ }^{\dagger}$ \\
\hline 1 factor omnibus & $0.098(0.092,0.103)$ & 0.79 & $353.78(6)^{*}$ \\
\hline 2 factor subjective vs objective & $0.078(0.072,0.084)$ & 0.87 & $190.63(5)^{*}$ \\
\hline 2 factor health literacy vs numeracy & $0.094(0.088,0.100)$ & 0.81 & $300.11(5)^{*}$ \\
\hline 4 factor & $0.055(0.049,0.061)$ & 0.94 & - \\
\hline
\end{tabular}

$* p<.001$

Chi-square difference test (compared to full, 4-factor model) 
Table 3 Intercorrelation matrix of the latent factors

\begin{tabular}{lllll}
\hline \hline & Literacy-objective & Literacy-subjective & Numeracy-objective & Numeracy-subjective \\
\hline Health literacy-objective & - & & & \\
Health literacy-subjective & $0.18^{*}$ & - & $-16^{*}$ & $0.56^{*}$ \\
Numeracy-objective & $0.43^{*}$ & $0.33^{*}$ & - & - \\
Numeracy-subjective & $0.53^{*}$ & & \\
\hline
\end{tabular}

${ }^{*} p<.001$

of colon cancer was not statistically significantly related to any of the health literacy or numeracy variables.

Unadjusted and adjusted models that predict knowledge from all four health literacy and numeracy measures are presented in Table 6. Adequate (vs. limited) objective and subjective health literacy and numeracy were associated with greater objective diabetes knowledge and greater objective colon cancer knowledge. Adequate subjective (but not objective) health literacy and numeracy were associated with more perceived diabetes knowledge. Perceived colon cancer knowledge was not significantly related to any of the health literacy or numeracy measures.

\section{DISCUSSION}

We recruited a large population-based sample to increase understanding of the nature of health literacy and numeracy. The data yielded three main findings: (1) objective and subjective measures of health literacy and numeracy represent four related but independent constructs; (2) from a clinical assessment perspective, the four measures are relatively consistent in their identification of individuals with adequate or limited facility with health information; (3) from a conceptual perspective, the four measures all uniquely relate to objective disease knowledge when considered simultaneously; and (4) the relationship between the health literacy/numeracy measures and perceived knowledge is different from their relationship with objective knowledge.

Prior work has examined the extent to which objective and subjective measures of health literacy, and objective measures of numeracy, correctly identify people with limited health literacy compared to a criterion standard. ${ }^{16}$ Others have compared objective and subjective measures of numeracy ${ }^{3,30}$ or health literacy, ${ }^{31}$ compared objective (but not subjective) measures of health literacy and numeracy, ${ }^{32}$ or examined the incremental benefit of adding a subjective health literacy measure to an objective measure. ${ }^{33}$ Such evaluations are partly intended to help researchers ascertain which measures most effectively identify people with limited health literacy, so that interventions can be developed and targeted appropriately.

However, that approach does not account for the possibility that the measures could be distinct constructs, and that each provides unique information about an individual's ability to make sense of and use health information. ${ }^{34}$ For example, some subjective measures may be measuring more meta-cognitive, emotional, or motivational aspects than actual ability. ${ }^{35}$ Nor does prior research generally describe how the four constructs in combination are related to key predictors of health decisions and behaviors such as health knowledge. ${ }^{2}$ Our research begins to fill that gap with data indicating that, although objective and subjective measures tend to be relatively consistent in categorizing people as having adequate or limited health literacy and numeracy, they are also unique constructs. Furthermore, each of the four constructs contributes meaningfully to objective knowledge about the risk factors of two major causes of morbidity and mortality. However, as illustrated by the fact that only subjective health literacy/ numeracy measures were associated with perceived diabetes knowledge, the measures are not interchangeable. Furthermore, the relationship between the health literacy measures and perceived knowledge may be different for different diseases; whereas subjective measures were important for perceived diabetes knowledge, they were not associated with perceived colon cancer knowledge. Future research should examine what, precisely, subjective measures of health literacy/numeracy are measuring, as well as what diseasespecific characteristics might drive differences in the ability

Table 4 Weighted Cross-Tabulation for Overlap in Measures

\begin{tabular}{|c|c|c|c|c|c|c|c|}
\hline \multicolumn{4}{|c|}{ Overlap of objective and subjective measures } & \multicolumn{4}{|c|}{ Overlap of health literacy and numeracy } \\
\hline & \multirow[t]{2}{*}{ Subjective } & \multicolumn{2}{|l|}{ Objective } & & \multirow[t]{2}{*}{ Health literacy } & \multicolumn{2}{|l|}{ Numeracy } \\
\hline & & Limited & Adequate & & & Limited & Adequate \\
\hline \multirow[t]{2}{*}{ Health literacy } & Limited & $40(6.52 \%)$ & $39(4.08 \%)$ & \multirow[t]{2}{*}{ Objective } & Limited & $143(18.91 \%)$ & $\begin{array}{l}63(6.81 \%) \\
564(51.42 \%)\end{array}$ \\
\hline & Adequate & $161(18.80 \%)$ & $751(70.59 \%)$ & & Adequate & $235(22.86 \%)$ & $564(51.42 \%)$ \\
\hline \multirow[t]{2}{*}{ Numeracy } & Limited & $226(26.69 \%)$ & $167(17.43 \%)$ & \multirow[t]{2}{*}{ Subjective } & Limited & $58(7.74 \%)$ & $21(2.97 \%)$ \\
\hline & Adequate & $142(14.50 \%)$ & $456(41.39 \%)$ & & Adequate & $329(36.17 \%)$ & $573(53.12 \%)$ \\
\hline
\end{tabular}


of subjective measures to predict perceived knowledge. One possibility is to examine whether the frightening nature of cancer $^{21,22}$ may have discouraged people from seeking cancer information, which could result in lower perceived knowledge.

These findings could be used by clinicians to guide conversations with patients. For example, objective health numeracy might be more important when conveying detailed treatment information, but when the goal is to understand how well a patient feels like they understand the information, the clinician might consider subjective health literacy instead. Researchers may consider basing their choice of what measure to include on the goal of the study. For example, a health communication intervention might focus more on objective numeracy, and a shared decision-making intervention might include both objective numeracy and health literacy. It could also be that, given

Table 5 Associations Between Individual Health Literacy Measures and Key Outcome Variables

\begin{tabular}{|c|c|c|c|c|c|c|}
\hline \multirow[b]{2}{*}{ Outcome } & \multicolumn{6}{|c|}{ Objective health literacy } \\
\hline & $\mathrm{b}^{\dagger \dagger}$ & $\begin{array}{c}\text { Unadjusted } \\
95 \% \mathrm{CI}\end{array}$ & $\mathrm{p}$ & $\mathrm{b}$ & $\begin{array}{c}\text { Adjusted* } \\
95 \% \mathrm{CI}\end{array}$ & $\mathrm{p}$ \\
\hline Diabetes knowledge & 1.21 & $1.01,1.40$ & $<.001$ & 1.03 & $0.81,1.24$ & $<.001$ \\
\hline Colon cancer knowledge & 1.19 & $0.96,1.41$ & $<.001$ & 0.96 & $0.71,1.21$ & $<.001$ \\
\hline Diabetes perceived knowledge & 0.09 & $-0.04,0.21$ & 0.17 & -0.02 & $-0.16,0.11$ & 0.72 \\
\hline \multirow[t]{2}{*}{ Colon cancer perceived knowledge } & -0.01 & $-0.13,0.12$ & 0.89 & -0.11 & $-0.24,0.03$ & 0.12 \\
\hline & \multicolumn{6}{|c|}{ Subjective health literacy } \\
\hline Outcome & $\mathrm{b}$ & $\begin{array}{c}\text { Unadjusted } \\
95 \% \mathrm{CI}\end{array}$ & $\mathrm{p}$ & $\mathrm{b}$ & $\begin{array}{c}\text { Adjusted } \\
95 \% \text { CI }\end{array}$ & $\mathrm{p}$ \\
\hline Diabetes knowledge & 1.16 & $0.87,1.44$ & $<.001$ & 0.87 & $0.58,1.16$ & $<.001$ \\
\hline Colon cancer knowledge & 0.99 & $0.66,1.32$ & $<.001$ & 0.65 & $0.31,0.99$ & $<.001$ \\
\hline Diabetes perceived knowledge & 0.32 & $0.15,0.50$ & $<.001$ & 0.23 & $0.05,0.41$ & 0.01 \\
\hline \multirow[t]{2}{*}{ Colon cancer perceived knowledge } & 0.19 & $0.01,0.37$ & 0.04 & 0.11 & $-0.07,0.29$ & 0.22 \\
\hline & \multicolumn{6}{|c|}{ Objective Numeracy } \\
\hline Outcome & $\mathrm{b}$ & $\begin{array}{c}\text { Unadjusted } \\
95 \% \mathrm{CI}\end{array}$ & $\mathrm{p}$ & $\mathrm{b}$ & $\begin{array}{c}\text { Adjusted } \\
95 \% \mathrm{CI} \\
\end{array}$ & $\mathrm{p}$ \\
\hline Diabetes knowledge & 0.89 & $0.72,1.07$ & $<.001$ & 0.72 & $0.53,0.90$ & $<.001$ \\
\hline Colon cancer knowledge & 0.84 & $0.64,1.05$ & $<.001$ & 0.58 & $0.37,0.80$ & $<.001$ \\
\hline Diabetes perceived knowledge & 0.11 & $0.00,0.22$ & 0.04 & 0.08 & $-0.04,0.19$ & 0.18 \\
\hline \multirow[t]{2}{*}{ Colon cancer perceived knowledge } & -0.03 & $-0.14,0.08$ & 0.60 & -0.08 & $-0.19,0.04$ & 0.20 \\
\hline & \multicolumn{6}{|c|}{ Subjective numeracy } \\
\hline Outcome & $\mathrm{b}$ & $\begin{array}{c}\text { Unadjusted } \\
95 \% \mathrm{CI}\end{array}$ & $\mathrm{p}$ & $\mathrm{b}$ & $\begin{array}{c}\text { Adjusted } \\
95 \% \text { CI } \\
\end{array}$ & $\mathrm{p}$ \\
\hline Diabetes knowledge & 0.74 & $0.56,0.91$ & $<.001$ & 0.56 & $0.37,0.75$ & $<.001$ \\
\hline Colon cancer knowledge & 0.72 & $0.52,0.93$ & $<.001$ & 0.46 & $0.24,0.68$ & $<.001$ \\
\hline Diabetes perceived knowledge & 0.25 & $0.14,0.36$ & $<.001$ & 0.22 & $0.11,0.34$ & $<.001$ \\
\hline Colon cancer perceived knowledge & 0.07 & $-0.04,0.18$ & 0.20 & 0.05 & $-0.07,0.17$ & 0.40 \\
\hline
\end{tabular}

*Adjusted for gender, age, racelethnicity, income, education, employment status, marital status, and metro status

${ }^{\dagger}$ All estimates are regression models comparing adequate (1) to limited (0). For example, compared to people with limited objective health literacy, people with adequate objective health literacy on average answer slightly more than 1 diabetes knowledge question correctly

All analyses are weighted using weights provided by GfK

Bolded numbers indicate statistical significance 
Table 6 Associations Between Health Literacy Measures and Key Outcome Variables with All Health Literacy Measures in the Model

\begin{tabular}{|c|c|c|c|c|c|c|}
\hline \multirow[b]{3}{*}{ Predictors } & \multicolumn{6}{|c|}{ Diabetes Knowledge } \\
\hline & \multicolumn{3}{|c|}{ Unadjusted } & \multicolumn{3}{|c|}{ Adjusted* } \\
\hline & $\mathrm{b}^{\dagger \dagger}$ & $95 \% \mathrm{CI}$ & $\mathrm{p}$ & $\mathrm{b}$ & $95 \% \mathrm{CI}$ & $\mathrm{p}$ \\
\hline Objective health literacy & 0.74 & $0.53,0.96$ & $<.001$ & 0.72 & $0.50,0.95$ & $<.001$ \\
\hline Subjective health literacy & 0.58 & $0.29,0.86$ & $<.001$ & 0.51 & $0.22,0.79$ & $<.001$ \\
\hline Objective numeracy & 0.41 & $0.23,0.60$ & $<.001$ & 0.41 & $0.22,0.60$ & $<.001$ \\
\hline \multirow[t]{3}{*}{ Subjective numeracy } & 0.32 & $0.14,0.50$ & $<.001$ & 0.32 & $0.13,0.51$ & 0.001 \\
\hline & \multicolumn{6}{|c|}{ Colon Cancer Knowledge } \\
\hline & \multicolumn{3}{|c|}{ Unadjusted } & \multicolumn{3}{|c|}{ Adjusted* } \\
\hline Predictors & $\mathrm{b}$ & $95 \% \mathrm{CI}$ & $\mathrm{p}$ & $\mathrm{b}$ & $95 \% \mathrm{CI}$ & $\mathrm{p}$ \\
\hline Objective health literacy & 0.79 & $0.54,1.04$ & $<.001$ & 0.76 & $0.50,1.02$ & $<.001$ \\
\hline Subjective health literacy & 0.44 & $0.11,0.77$ & 0.010 & 0.35 & $0.02,0.69$ & 0.040 \\
\hline Objective numeracy & 0.38 & $0.16,0.60$ & 0.001 & 0.30 & $0.08,0.53$ & 0.008 \\
\hline Subjective numeracy & 0.32 & $0.11,0.53$ & 0.003 & 0.26 & $0.03,0.48$ & 0.024 \\
\hline
\end{tabular}

Diabetes Perceived Knowledge

\begin{tabular}{lcccccc} 
& \multicolumn{3}{c}{ Unadjusted } & \multicolumn{3}{c}{ Adjusted* } \\
\cline { 2 - 7 } Predictors & $\mathrm{b}$ & $95 \% \mathrm{CI}$ & $\mathrm{p}$ & $\mathrm{b}$ & $95 \% \mathrm{CI}$ & $\mathrm{p}$ \\
\hline Objective health literacy & -0.07 & $-0.21,0.07$ & 0.34 & -0.13 & $-0.27,0.02$ & 0.09 \\
Subjective health literacy & 0.27 & $0.09,0.46$ & $\mathbf{0 . 0 0 4}$ & 0.22 & $0.04,0.41$ & $\mathbf{0 . 0 1 8}$ \\
Objective numeracy & 0.01 & $-0.12,0.13$ & 0.92 & 0.03 & $-0.09,0.15$ & 0.64 \\
Subjective numeracy & 0.24 & $0.12,0.35$ & $<.001$ & 0.22 & $0.10,0.34$ & $<.001$ \\
\hline & \multicolumn{4}{c}{ Colon Cancer Perceived Knowledge } \\
\cline { 2 - 8 } & $\mathrm{b}$ & Unadjusted & \multicolumn{5}{c}{ Adjusted* } \\
\hline Predictors & -0.04 & $-0.18,0.10$ & 0.60 & -0.11 & $-0.25,0.04$ & 0.14 \\
\hline Objective health literacy & 0.19 & $0.00,0.38$ & 0.05 & 0.13 & $-0.05,0.32$ & 0.16 \\
Subjective health literacy & -0.06 & $-0.19,0.06$ & 0.33 & -0.07 & $-0.19,0.05$ & 0.26 \\
Objective numeracy & 0.09 & $-0.03,0.21$ & 0.15 & 0.08 & $-0.05,0.20$ & 0.22 \\
Subjective numeracy & &
\end{tabular}

*Adjusted for gender, age, racelethnicity, income, education, employment status, marital status, and metro status

${ }^{\prime}$ All estimates are regression weights comparing adequate (1) to limited (0). For example, compared to people with limited objective health literacy, people with adequate objective health literacy on average answer almost 1 additional diabetes knowledge question correctly, even after controlling for the other health literacy and numeracy variables in the model

${ }^{7}$ All analyses are weighted using weights provided by GfK

Bolded numbers indicate statistical significance

the high percentage of overlap in categorizing people as having limited facility with health information, as well as the low percentage of people who were high in numeracy but low in health literacy (Table 3), clinicians and researchers might consider assessing objective health literacy in situations where only one measure can be assessed.

Several limitations should be considered. First, GfK panelists might have different health literacy and numeracy levels 
than the general population, but due to an absence of data about health literacy and numeracy in the GfK survey panel, we do not know how this might have affected our findings. However, because the weighting procedures ensure that the distribution of key demographic variables associated with health literacy in the GfK panel is similar to the overall US population, this problem may be minor. Second, there are many measures of objective and subjective health literacy and numeracy, and our study examined only one measure for each construct. A different selection of measures might produce different findings. Future research should explore this possibility. Other limitations that could limit the generalizability of the findings include an English-language survey, a highly educated sample, and examining only two disease contexts.

\section{CONCLUSION}

This is one of the first studies to identify objective and subjective health literacy and numeracy as four distinct but related concepts and, furthermore, to determine that each construct has a key role in predicting knowledge of risk factors of two major diseases: colon cancer and diabetes. This suggests that, until research uncovers what psychological processes drive subjective measures (e.g., motivation, self-efficacy), research investigating the relationship between health literacy and health outcomes should consider assessing all four measures and clinicians should consider using "universal precautions" by simplifying communications with all patients. ${ }^{36}$

Corresponding Author: Erika A. Waters, PhD, MPH; Washington University in St. Louis, 660 S. Euclid Ave, Campus Box 8100, St. Louis, MO 63110, USA (e-mail: waterse@wustl.edu).

Funding This work was supported by funding from the National Cancer Institute (R01CA197351, PI: Orom).

\section{Compliance with Ethical Standards:}

All study materials and procedures were approved by the University of Buffalo Institutional Review Board, but recruitment and data collection were conducted through GfK.

Conflict of Interest: The authors declare that they do not have a conflict of interest.

\section{REFERENCES}

1. Hunleth JM, Steinmetz EK, McQueen, A, James AS. Beyond Adherence: Health Care Disparities and the Struggle to Get Screened for Colon Cancer. Qual Health Res. 2015.

2. Kutner M, Greenberg E, Jin Y, Paulsen C. The health literacy of America's adults: Results from the 2003 National Assessment of Adult Literacy. Washington, DC: U.S. Department of Education, National Center for Health Statistics; 2006. Report No.: NCES 2006-483.

3. Nelson WL, Moser RP, Han PK. Exploring objective and subjective numeracy at a population level: findings from the 2007 Health Information National Trends Survey (HINTS). J Health Commun. 2013;18(2): 192-205.
4. Fernandez DM, Larson $\mathbf{J}$, Zikmund-Fisher BJ. Associations between health literacy and preventive health behaviors among older adults: findings from the health and retirement study. BMC Public Health. 2016;16.

5. Reyna VF, Nelson WL, Han PK, Dieckmann NF. How numeracy influences risk comprehension and medical decision making. Psychol Bull. 2009;135(6):943-73.

6. Fan JH, Lyons SA, Goodman MS, Blanchard MS, Kaphingst KA. Relationship Between Health Literacy and Unintentional and Intentional Medication Nonadherence in Medically Underserved Patients With Type 2 Diabetes. Diabetes Educ. 2016;42(2):199-208.

7. Berkman ND, Sheridan SL, Donahue KE, Halpern DJ, Viera A, Crotty $\mathbf{K}$, et al. Health Literacy Interventions and Outcomes: An Updated Systematic Review. Rockville, MD: Agency for Healthcare Research and Quality; 2011.

8. Hay JL, Orom H, Kiviniemi MT, Waters EA. "I don't know" my cancer risk: exploring deficits in cancer knowledge and information-seeking skills to explain an often-overlooked participant response. Med Decis Making. 2015;35(4):436-45.

9. Oh A, Shaikh A, Waters E, Atienza A, Moser RP, Perna F. Health disparities in awareness of physical activity and cancer prevention: findings from the National Cancer Institute's 2007 Health Information National Trends Survey (HINTS). J Health Commun. 2010;15 Suppl 3:60-77.

10. Kaphingst KA, Blanchard M, Milam L, Pokharel M, Elrick A, Goodman MS. Relationships Between Health Literacy and GenomicsRelated Knowledge, Self-Efficacy, Perceived Importance, and Communication in a Medically Underserved Population. J Health Commun. 2016;21 Suppl 1:58-68.

11. Weiss BD, Mays MZ, Martz W, Castro KM, DeWalt DA, Pignone MP, et al. Quick assessment of literacy in primary care: The newest vital sign. Ann Fam Med. 2005;3(6):514-22.

12. Arozullah AM, Yarnold PR, Bennett CL, Soltysik RC, Wolf MS, Ferreira RM, et al. Development and validation of a short-form, rapid estimate of adult literacy in medicine. Med Care. 2007;45(11):1026-33.

13. Lipkus IM, Samsa G, Rimer BK. General performance on a numeracy scale among highly educated samples. Med Decis Making. 2001;21(1):37-44.

14. Chew LD, Griffin JM, Partin MR, Noorbaloochi S, Grill JP, Snyder A, et al. Validation of screening questions for limited health literacy in a large VA outpatient population. J Gen Intern Med. 2008;23(5):561-6.

15. McNaughton CD, Cavanaugh KL, Kripalani S, Rothman RL, Wallston KA. Validation of a short, 3-item version of the subjective numeracy scale. Med Decis Making. 2015;35(8):932-6. https://doi.org/10.1177/ 0272989x15581800.

16. Carpenter CR, Kaphingst KA, Goodman MS, Lin MJ, Melson AT, Griffey RT. Feasibility and diagnostic accuracy of brief health literacy and numeracy screening instruments in an urban emergency department. Acad Emerg Med. 2014;21(2):137-46.

17. Weinstein ND, Sandman PM. The precaution adoption process model. In: Glanz K, Rimer BK, Lewis FM, eds. Health behavior and health education: Theory, research, and practice. 3rd ed. San Francisco, CA: John Wiley and Sons; 2002:121-43.

18. Orom H, Schofield E, Kiviniemi MT, Waters EA, Biddle C, Chen X, et al. Why do people frequently not know their risk for common diseases? An investigation of potential mechanisms. under review.

19. Centers for Disease Control. Diabetes: Who's at risk? 2017 Accessed on July 11, 2018. Available from: https://www.cdc.gov/diabetes/basics/ risk-factors.html.

20. American Cancer Society. Colorectal Cancer Risk Factors 2017. Accessed on July 11, 2018. Available from: https://www.cancer.org/cancer/colonrectal-cancer/causes-risks-prevention/risk-factors.html.

21. Emanuel AS, Kiviniemi MT, Howell JL, Hay JL, Waters EA, Orom H, et al. Avoiding cancer risk information. Soc Sci Med. 2015;147:113-20.

22. Moser RP, Arndt J, Han P, Waters EA, Amsellem M, Hesse BW. Perceptions of Cancer as a Death Sentence: Prevalence and Consequences. J Health Psychol. 2014;19(12):1518-24.

23. Weiss BD, Mays MZ, Martz W, Castro KM, DeWalt DA, Pignone MP, et al. Quick assessment of literacy in primary care: the newest vital sign. Ann Fam Med. 2005;3(6):514-22.

24. Chew LD, Bradley KA, Boyko EJ. Brief questions to identify patients with inadequate health literacy. Fam Med. 2004;36(8):588-94.

25. Schwartz LM, Woloshin S, Black W, Welch G. The role of numeracy in understanding the benefit of screening mammography. Ann Intern Med. 1997; 127(11):966-72.

26. Muthén LK, Muthén Bo. Mplus Version 8. 2017.

27. StataCorp. Stata Statistical Software: Release 14. College Station, TX: StataCorp LP: 2015. 
28. Hu L, Bentler PM. Evaluating model fit. In: Hoyle RH, editor Structural Equation Modeling. Thousand Oaks, CA: Sage Publications; 1999. p. 76-99.

29. Iacobucci D. Structural equations modeling: Fit indices, sample size, and advanced topics. J Consum Psychol. 2010;20(1):90-8

30. Dolan JG, Cherkasky OA, Li Q, Chin N, Veazie PJ. Should Health Numeracy Be Assessed Objectively or Subjectively? Med Decis Making. 2016;36(7):868-75

31. Kiechle ES, Bailey SC, Hedlund LA, Viera AJ, Sheridan SL. Different Measures, Different Outcomes? A Systematic Review of PerformanceBased versus Self-Reported Measures of Health Literacy and Numeracy. J Gen Intern Med. 2015;30(10):1538-46.

32. Griffey RT, Melson AT, Lin MJ, Carpenter CR, Goodman MS, Kaphingst KA. Does numeracy correlate with measures of health literacy in the emergency department? Acad Emerg Med. 2014;21(2):147-53.
33. Goodman MS, Griffey RT, Carpenter CR, Blanchard M, Kaphingst KA. Do Subjective Measures Improve the Ability to Identify Limited Health Literacy in a Clinical Setting? J Am Board Fam Med. 2015;28(5):584-94.

34. Storch D, Jackson JL. Capsule Commentary on Kiechle et al. Different Measures, Different Outcomes? A Systematic Review of PerformanceBased versus Self-Reported Measures of Health Literacy and Numeracy. J Gen Intern Med. 2015;30(10):1537.

35. Peters E, Bjalkebring P. Multiple numeric competencies: When a number is not just a number. J Pers Soc Psychol. 2015;108(5):802-22.

36. Agency for Healthcare Research and Quality. AHRQ Health Literacy Universal Precautions Toolkit Rockville, MD; 2016. Accessed on July 11, 2018. Available from: http://www.ahrq.gov/professionals/ quality-patient-safety/quality-resources/tools/literacy-toolkit/index.html. 